\title{
Freud e a prevenção: um percurso de controvérsias
}

\author{
Beatriz Sernache de Castro Neves, (DiD ${ }^{I \star}$ Maria Celina Peixoto Lima $(\mathbb{D})$ II \\ ${ }^{I}$ Universidade Federal do Ceará, Fortaleza, CE, Brasil

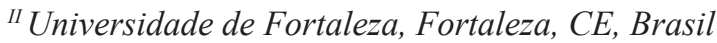

\begin{abstract}
Resumo
O termo prevenção em saúde vem sendo utilizado desde a mudança no paradigma médico com certa frequência dentro e fora do campo da medicina. Entretanto, ao se debater esse conceito fora desse campo, torna-se necessário trazer algumas particularidades em questões atravessadas pelo tempo e espaço em que se dão. Este artigo problematiza a ideia de prevenção no pensamento de Freud. Assim, investigam-se, a partir de uma revisão dos seus escritos, os diversos empregos e concepções que ele faz dos termos prevenção e profilaxia. Com origem nos textos de 1896, passando por outros textos em 1910, 1913, 1926, 1934 até os artigos mais tardios de 1937, destacam-se suas principais elaborações sobre a temática, marcadas por uma flutuação de posicionamentos referentes às possibilidades e limites de uma prática psicanalítica de caráter preventivo. Para auxiliar na articulação utilizamos também escritos de outros psicanalistas sobre o tema, com o objetivo de reatualizar o debate da noção de prevenção em psicanálise.
\end{abstract}

Palavras-chave: psicanálise; prevenção; profilaxia.

\section{Freud and prevention: a controversial trajectory}

\begin{abstract}
The term health prevention has been used since the medical paradigm shift quite often within and outside the field of medicine. However, when discussing this concept outside of the field, it is necessary to bring some particularities in question with regards to the time and space in which they occur. The present paper discusses the idea of prevention in Freud's thinking. Thus, from a review of his writings, the various uses and conceptions he makes of the terms prevention and prophylaxis are investigated. Originating in the 1896 texts and going through others in 1910,1913, 1926, 1934 until the later articles of 1937, his main elaborations on the subject are highlighted, marked by a fluctuation of positions regarding the possibilities and limits of a preventive psychoanalytic practice. To assist in the articulation we will also use writings of other psychoanalysts on the subject, with the aim of updating the debate on the notion of prevention in psychoanalys
\end{abstract}

Keywords: psychoanalysis; prevention; prophylaxis.

\section{Introdução}

As ações voltadas para a prevenção no campo da medicina testemunham a mudança operada há mais de meio século na racionalidade médica, decorrente da criação da Organização Mundial de Saúde - OMS e da ideia positivada de saúde como bem-estar biopsicossocial. Surgem, a partir de então, segundo Anne Golse (2001), dois novos paradigmas da medicina contemporânea, configurados na etiologia plurifatorial e no fator de risco. Este permitirá uma reorganização do discurso médico e o estabelecimento de uma política global de saúde orientada em ações sobre os fatores. De um lado, tais ações terão como meta o desenvolvimento de fatores positivos, constituindo o que será tomado como a promoção da saúde; por outro lado, ações positivas de redução ou supressão de fatores de risco, relativas ao que é da ordem da prevenção.

As repercussões da nova racionalidade médica no campo da saúde mental foram objeto de um importante estudo de Robert Castel (1981) no início dos anos 1980. Constatando a crise da psiquiatria social e da psicanálise, o autor já preconizava a preponderância de novas estratégias médico-psicológicas e sociais que, desde então, organizariam as práticas, sobretudo preventivas, as quais se caracterizam como rastreadoras dos riscos.

\footnotetext{
^Endereço para correspondência: Universidade Federal do Ceará. Rua Professor Costa Mendes, 1608, Bloco didático, $5^{\circ}$ andar. Rodolfo Teófilo - Fortaleza, CE - Brasil CEP: 60.430-140.Emails: bia sernache@hotmail.com, celina.lima@unifor.br Os dados completos das autoras encontram-se ao final do artigo.
}

Passados 35 anos da publicação do livro de Castel (1981), A gestão dos riscos firma-se como estatuto social não só da psiquiatria contemporânea, mas também do conjunto de disciplinas que têm como alvo o saber e a prática no campo da saúde mental.

Nesse contexto, cabe-nos interrogar: de que modo a psicanálise poderia contribuir para o debate, por meio da inserção dos seus pressupostos teórico-metodológicos? A larga experiência acumulada pela clínica psicanalítica seria passível de uma extensão às novas demandas do laço social? Como pensar esses paradigmas organizadores da nova racionalidade médica, a princípio estranhos ao discurso da psicanálise, em uma prática atenta ao sujeito?

A inserção do psicanalista em contextos institucionais o confronta, muitas vezes, com a situação paradoxal de conjugar a psicanálise e a prevenção, implicando, dessa forma, uma conduta normativa submetida a protocolos e estatísticas, com a pretensão de prevenir transtornos de conduta ou de comportamento. Em razão desse confronto, resta a cada psicanalista atualizar a tarefa, inaugurada por Freud, de sustentar uma posição subversiva para resistir à tal injunção social, não bastando uma atitude de recusa à interlocução, justificada pela incompatibilidade de propósitos, mas assumindo, como procedeu Freud, uma posição de engajamento político perante novos contornos do mal-estar social.

Com efeito, a proposta de um trabalho de leitura da obra de Freud em busca de suas posições quanto à prevenção, mais do que um exercício acadêmico de revisão

Recebido em: 19 de junho de 2016

$1^{\text {a }}$ avaliação: 21 de setembro de 2018 $2^{\mathrm{a}}$ avaliação: 12 de julho de 2019 Aceito em: 19 de agosto de 2019 
de literatura, constitui um esforço de resgate desse engajamento ético e político inaugural, e, por consequência, um movimento de resistência às forças do recalcamento que ameaçam apagar o projeto freudiano.

Veremos que as principais elaborações freudianas sobre a prevenção são marcadas por uma flutuação de posicionamentos cujo percurso já se iniciou nos primórdios de sua obra, em 1896, e se desdobram até os artigos tardios de 1937. Se, no primeiro momento, a ideia de prevenção vai ganhando delimitação com relação ao sentido de uma profilaxia médica, como resultado do desenvolvimento teórico-clínico acerca da neurose de transferência, mais tarde a reconfiguração do campo psicanalítico, produzida pela segunda tópica e pelo segundo dualismo pulsional, incidirá claramente sobre a ideia de prevenção.

\section{Da concepção médica de profilaxia das neuroses}

Freud (1898/2006), no artigo intitulado $A$ sexualidade na etiologia das neuroses, aponta que a masturbação é a causa da neurastenia na juventude e que, posteriormente, poderia causar a neurose de angústia. Aqui, o autor considera que a sua ausência pode constituir benefício para os neurastênicos como profilaxia.

Freud situava a neurastenia como uma das neuroses atuais, resultantes diretas da inadequação, ou até mesmo da ausência da excitação sexual, e cujo protótipo era a masturbação compulsiva. A masturbação - tanto feminina quanto masculina - para Freud (1898/2006a) merecia atenção especial. Ele considerava que a neurastenia havia exibido aumento de casos naquela época. Sugeriu, então, que era de interesse público que os homens ingressassem na relação sexual com toda a sua potência. Mesmo assim, em matéria de profilaxia, o indivíduo ficava desamparado.

Para que a profilaxia fosse possível, Freud acreditava que a comunidade deveria se interessar por tal assunto, dando apoio e criando regulamentos aceitáveis. Achava, no entanto, que a sociedade da época estava distante disso e que, na verdade, a civilização contribuía para a disseminação da neurastenia. Freud (1898/2006a) enumerou uma série de questões (uma geração de médicos que não se recordam de sua juventude, o orgulho dos pais, o puritanismo das mães, entre outras) a serem trabalhadas em prol da diminuição de casos, e apontou a necessidade de se criar um espaço público para debater esse tema, que levaria o tempo necessário até que a população aprendesse a conviver com as reivindicações da sexualidade.

Estamos em um momento no qual, de acordo com Catherine Millot (1987), Freud ainda depositava esperanças na função educativa/profilática do médico. A autora destaca a carta que Freud escreveu a Fliess, pela qual podemos concluir que a prevenção de transtornos sexuais é confundida com a de doenças, como sífilis e blenorragia, tidas como perigos que ameaçavam a todos os que renunciavam à masturbação. A solução seria a autorização para manter relações de forma livre entre moças e rapazes de boa família, desde que, à época, houvesse métodos contraceptivos eficazes. Para Freud (1893 apud MILLOT, 1987), na falta de alternativas possíveis, a sociedade fi- caria condenada a se tornar vítima de neuroses que diminuíam a alegria, dificultavam as relações conjugais e poderiam perpetuar essas questões para futuras gerações.

Millot (1987) destaca que, nesse momento, Freud está situado em uma posição estritamente médica, e não moral ou política. Acreditava que, na medida em que se criassem métodos anticoncepcionais, seria possível conciliar as exigências da sexualidade com as da sociedade.

Com a introdução de seus estudos sobre a histeria, abre-se outra categoria nosográfica, cuja etiologia está não mais em condutas inadequadas, mas na própria vida mental. Sua concepção de neurose de defesa o leva à constatação do vínculo de quadros neuróticos com a questão da moral sexual da época. Freud, dessa maneira, denuncia os abusos de uma moral sexual que, além de reprimir os atos, proibia os pensamentos, podendo causar a inibição da atividade intelectual. O tratamento analítico buscava tornar possível a entrada de uma palavra no lugar do sintoma. $\mathrm{O}$ que põe obstáculo para a palavra, segundo Freud, opõe-se ao próprio progresso da civilização (MILLOT, 1987).

Em outra carta a Fliess, Freud inverte o problema sobre a moral (MILLOT, 1987). A origem do recalque da sexualidade não estaria mais estritamente relacionada à moral, mas à natureza da pulsão sexual. Visto desse modo, a causa da neurose não estava na moral - a moralidade propriamente dita tem força demonstrada na neurose, pois a sexualidade em si é essencialmente perturbadora. A moral deve ser, portanto, considerada como uma dentre outras maneiras de os homens se protegerem de sua sexualidade.

Aqui podemos perceber o primeiro movimento referente à abordagem da prevenção. Na medida em que o autor muda a teoria da etiologia das neuroses, também produz uma mudança de posição relacionada à possibilidade de prevenção, como veremos a seguir.

No texto As perspectivas futuras da psicanálise, Freud (1910/2006c) acentua que algumas pessoas, quando se deparam com conflitos em suas vidas, fogem para a neurose, obtendo ganhos secundários com essa iniciativa. Algum tempo depois, entretanto, esse caminho pode acarretar bastante prejuízo. O autor argumenta que a psicanálise funciona como reveladora de algumas questões, impelindo as pessoas à honestidade e à confissão acerca das pulsões sob cuja orientação estão agindo. Além disso, ela contribui para que o paciente lute por aquilo que deseja ou renuncie a esses desejos, e que a sociedade, após o esclarecimento proporcionado pela psicanálise, pode ajudá-lo nessa tarefa.

Nesse texto, Freud (1910/2006c) observa que a prevenção das doenças neuróticas não seria vantajosa para todas as pessoas. Aquelas pessoas que fogem dos conflitos refugiando-se na neurose não suportariam enfrentá-los, e um confronto dessa natureza poderia até mesmo lhes causar piora. Com efeito, Freud considera que as neuroses têm funções biológicas, atuantes como um dispositivo protetor. Mais adiante, Freud (1910/2006c) aponta que as energias gastas na produção de sintomas neuróticos, que servem ao mundo da fantasia, algumas vezes isolados da 
realidade, fortalecem o clamor por modificações reivindicadas pela civilização, podendo resultar em bem-estar para as gerações futuras. Em suas palavras:

Desejaria, portanto, deixá-los ir com a segurança de que, ao trabalharem seus pacientes psicanaliticamente, estarão cumprindo com o seu dever, em mais de um sentido. Os senhores não estarão trabalhando, apenas, a serviço da ciência, ao fazer uso de uma única oportunidade, para descobrir os segredos das neuroses; estarão, não apenas, dando aos seus pacientes o remédio mais eficaz para os seus sofrimentos, de que dispõem hoje em dia; estarão contribuindo, com a sua parcela, para o esclarecimento da comunidade, através do qual esperamos alcançar a profilaxia mais radical, contra as perturbações neuróticas, ao longo do caminho indireto da autoridade social (FREUD, 1910/2006c).

Destacamos o final da citação, quando Freud propõe, de forma enigmática, que o caráter profilático do trabalho do analista está mais radicalmente relacionado ao "esclarecimento da comunidade [...] ao longo do caminho indireto da autoridade social". Estaria ele aí antecipando sua reflexão, que foi desenvolvida pouco tempo depois sobre o interesse da psicanálise pelo campo da educação? A "autoridade social", apontada como a mediadora do trabalho preventivo, seria, na concepção de Freud, o educador?

\section{Da esperança de uma educação psicanaliticamente orientada...}

Freud se dedicou, em vários momentos de sua obra, a refletir sobre as convergências e divergências entre as práticas educativa e psicanalítica. No artigo $O$ interesse cientifico da psicanálise (FREUD, 1913/2006d), ao falar do interesse educacional da psicanálise, acreditava que ela poderia ajudar na tarefa educativa ao elucidar certas fases do desenvolvimento infantil. Acreditava ainda que, com suporte em tal esclarecimento, os educadores não iriam subestimar a importância dos impulsos instintivos considerados imprestáveis para a sociedade. No lugar disso, poderiam se abster da tentativa de reprimir esses impulsos pela força, na medida em que aprendessem que eles podem produzir resultados também indesejáveis, como a alternativa de dar livre acesso às crianças para suas travessuras. A supressão desses instintos conduz à repressão, que pode futuramente causar predisposição a doenças nervosas. Consoante a reflexão freudiana,

A psicanálise tem frequentes oportunidades de observar o papel desempenhado pela severidade inoportuna e sem discernimento da educação na produção de neuroses, ou o preço, em perda de eficiência e capacidade de prazer, que tem de ser pago pela normalidade na qual o educador insiste. E a psicanálise pode também demonstrar que preciosas contribuições para a formação do caráter são realizadas por essas pulsões associais e perversas na criança, se não forem submetidas à repressão, e sim desviadas de seus objetivos originais para outros mais valiosos, através do processo conhecido como "sublimação" (FREUD, 1913/2006d).

Afinal, para o autor, as maiores virtudes nascem exatamente da formação reativa e da sublimação vindas das piores disposições. Dessa maneira, conclui a ideia de que

Fractal, Rev. Psicol., v. 31 - n. 3, p. 313-319, 2019 tudo aquilo que se pode esperar no plano da profilaxia das neuroses está nas mãos de uma educação psicanaliticamente esclarecida.

Millot (1987) considera que as descobertas sobre a sexualidade infantil atraíram o interesse de Freud para a educação, assim como seus estudos acerca da importância dos primeiros anos de vida na etiologia das neuroses. Suas investigações sobre o desenvolvimento infantil trazem à superfície, também, as influências vindas da educação. Com essas descobertas, a psicanálise teria a possibilidade de esclarecer aos educadores o seu poder, mostrando-lhes seus erros e permitindo, dessa forma, uma melhor atuação. A esperança de Freud, segundo a autora, era saber o que se está fazendo quando se educa, visto que não se faz o que se quer. Vale ressaltar, ainda, que, para Freud, as práticas educacionais repressivas causavam prejuízo ao desenvolvimento dos interesses intelectuais, visto que a repressão excessiva vinda da educação no concernente à curiosidade sexual poderia causar o recalque, inibindo as possíveis curiosidades intelectuais futuras.

Freud acreditava na prevenção das neuroses mediante a possibilidade de esclarecimento às crianças. $\mathrm{O}$ educador deveria manifestar respeito pela verdade e pela liberdade de expressão dada às crianças. Assim como a psicanálise valoriza o poder da palavra, tido como o princípio da cura analítica, é na palavra que a educação deveria se ancorar, no sentido de colaborar com a criança na superação de seus conflitos psíquicos (MILLOT, 1987).

Schimidt (2011) considera que Freud buscava um ideal de educação, uma matriz de intervenções junto às crianças, que possibilitasse torná-las adultos sem adoecimentos psíquicos. Portanto, uma educação com efeitos profiláticos. Seria uma nova pedagogia, que aliaria noções do campo da educação e algumas outras da psicanálise. Resumida por Schimidt (2011), essa pedagogia almejava o equilíbrio para as crianças em meio ao processo civilizacional. No entanto, Schimidt acredita que Freud não apostava tudo nessa educação que regulasse quantidades de restrições ou mesmo de satisfação pulsional, com o objetivo de prevenir neuroses ou perversões. Entretanto, Freud alimentava, sim, as esperanças de outra feição educativa, psicanaliticamente esclarecida, na qual as atitudes de pais e professores, em sua relação transferencial com as crianças, pudessem alterar, em gerações futuras, o modo pedagógico responsável pelo cumprimento imperfeito de seus objetivos.

Schimidt (2011), apoiando-se em Millot (1987), considera a existência do primeiro Freud, soterrado pela conceituação da pulsão de morte, cujo efeito originou o segundo Freud em termos de concepção de educação. Num texto de 1912, Freud relata que existe um resto de insatisfação inerente à natureza da pulsão sexual, origem de importantes realizações culturais, e que, por ser impossível que a pulsão sexual e as exigências culturais entrem em harmonia, o desprazer passa a ser o meio único para a educação. Schimidt (2011) conclui que a defesa contra a ameaça do desprazer inevitável tem o poder de organizar ou educar psiquicamente. O que fica para a educação é o lugar de agente da sublimação, que leva as 
crianças às realizações culturais. Schimidt (2011) considera a sublimação como a capacidade da pulsão sexual de substituir seus objetivos mais imediatos por outros, sem caráter sexual, que tenham a possibilidade de ser mais valorizados. Sendo assim, a pulsão modifica o seu objetivo para poder satisfazer-se, atingindo outro ponto não sexual, e são seus maiores exemplos as atividades culturais e intelectuais. Com origem na sublimação, a pulsão é substituída, em vez de ser reprimida a qualquer custo. Com essas noções, Freud enterra a ideia da existência de uma educação em que não haveria desprazer psíquico.

Nesse sentido, Lajonquière (2006) salienta que Freud, na verdade, não se iludiu com a possibilidade de uma educação menos repressiva, embora sempre almejasse uma qualidade diferente das relações entre adultos e crianças. Ele esperava uma intervenção na qual os adultos pudessem endereçar a palavra às crianças em nome de outras coisas além da moral vigente, o que definiria a expressão de educação para a realidade.

Terão de admitir para si mesmos toda a extensão de seu desamparo e insignificância na maquinaria do universo; não podem mais ser o centro da criação, o objeto de terno cuidado por parte de uma Providência beneficente [...] Os homens não podem permanecer crianças para sempre; têm de, por fim, sair para a vida "hostil". Podemos chamar isso de educação para a realidade (FREUD, 1927/2006g).

O termo 'realidade' aqui colocado abrange a realidade do desejo, conceituado como o que condena o homem a estar sempre fora de foco consigo mesmo e com o outro.

Lajonquière (2006) acredita que a ideia de prevenir neuroses e perversões através da educação está ligada à desconsideração da estrutura paradoxal do desejo, induzida por uma certa leitura freudiana. $\mathrm{O}$ autor pondera que essa leitura parcial das obras de Freud aconteceu em razão do contexto em que foi feita, antes da proposta lacaniana de retorno ao criador da psicanálise. Essa leitura parcial da obra esquece a advertência de Freud (1937/2006i) no texto Análise terminável e análise interminável, que será comentada mais à frente.

\section{...ao trabalho analítico com crianças}

Somos já bem advertidos do fato de que a clínica com adultos neuróticos constitui a via privilegiada, empreendida por Freud, de acesso à vida sexual infantil. $\mathrm{O}$ caso do pequeno Hans, trabalhado no texto Análise de uma fobia em um menino de cinco anos (FREUD, 1909/2006b), possibilita-lhe, no entanto, aceder a um novo elemento: a constatação da possibilidade de intervenção antes da instalação da neurose. Portanto, abre-se a discussão sobre a viabilidade de um trabalho analítico pré-recalque, com implicações evidentes que incidirão sobre a problemática da prevenção. Será preciso, no entanto, esperar pela virada metapsicológica produzida pelo conceito de pulsão de morte e de repetição, para que essa discussão ganhe novos contornos, inclusive no que diz respeito à interface da psicanálise com a educação.

No final do artigo A questão da análise leiga, Freud (1926/2006f) retoma o ponto relativo à educação. De acordo com ele, caso a criança apresente sinais de de- senvolvimento indesejável, tornando-se mal-humorada, indócil, desatenta, ou até mesmo apresente sintomas neuróticos claros (nervosismo, perda de apetite, vômitos ou insônia), o médico nada tem a esclarecer.

Freud (1926/2006f) sugere que, na opção por um tratamento que combine a influência psicanalítica com medidas educacionais, ministrado por pessoas que se interessem pela vida mental das crianças, podem acontecer duas coisas, simultaneamente: a eliminação de sintomas neuróticos e até mesmo a reversão da mudança de caráter que já tinha começado. O reconhecimento da importância das neuroses infantis como causadoras de doenças mais graves no futuro aponta para o direcionamento da análise infantil como um método de profilaxia. Mais adiante, o autor acentua que a civilização da época merecia um corretivo, por impor uma pressão intolerável. Com isso em vista, Freud (1926/2006f) se questiona se será destinado à psicanálise esse papel.

Freud (1933/2006h) retomou o tema da profilaxia, quando se expressou acerca das possíveis interseções entre psicanálise e educação, no texto Explicações, aplicações e orientações. O autor, dissertando sobre as possibilidades da análise infantil, reconheceu que grande parte das crianças passa por uma fase neurótica, e seria interessante se pensar em medidas profiláticas para lidar com elas. Aponta que o objetivo da educação é inibir, proibir e suprimir, e essa supressão das pulsões está relacionada ao risco de doenças neuróticas. A educação deve, portanto, atingir o máximo com o mínimo de dano. Sendo assim, caso descubra o ponto ótimo e execute suas tarefas de maneira ideal, pode eliminar uma das origens da etiologia do adoecer, a influência dos traumas na infância.

Considerando a dificuldade do educador no reconhecimento da individualidade da criança e na percepção de pequenos sinais indicadores de sofrimento psíquico, Freud conclui que a formação do educador não pode prescindir da psicanálise, e mesmo da análise pessoal do educador, já que a assimilação dos preceitos psicanalíticos não se dá sem uma experiência analítica propriamente dita. A análise de professores seria, assim, a medida profilática de maior eficiência do que a análise das crianças propriamente dita.

Millot (1987) chama a atenção para o fato de que Freud acreditava que as críticas de pais e educadores que lhe eram dirigidas ao defender a ideia da sexualidade infantil decorriam da ação do recalque ao qual estavam submetidos. Segundo a autora, Freud observava nessa realidade os efeitos da amnésia infantil, do recalque, do esquecimento das primeiras experiências sexuais infantis. Dessa forma, as excessivas repressões exercidas pela educação justificavam-se pela intensidade do recalque dos próprios educadores, e levaram Freud a concluir que o melhor seria se esses profissionais pudessem fazer uma análise pessoal.

Millot (1987) relembra também o fato de que algumas perguntas feitas por crianças nessa fase da vida são respondidas por adultos em forma de fábulas ou com reprovação. Para Freud, esse tipo de atitude é extremamente prejudicial ao desenvolvimento infantil. Em muitos casos, 
é a primeira ocorrência de um conflito psíquico, que pode causar uma cisão psíquica precoce. Em outros casos, a confiança das crianças nos adultos fica abalada. Nesse sentido, a censura exercida sobre a palavra mediante o encobrimento de verdades, assim como omissões, é considerada por Freud um erro educacional cheio de consequências, visto que, ao provocar os sintomas neuróticos, nos quais a verdade recalcada voltará, poderia também atrapalhar a função intelectual, assim como a independência do pensamento. A educação sexual, na perspectiva de Millot (1987), apoiando-se nessa constatação freudiana, poderia ter valor de prevenção quanto às neuroses, pois preservaria o bom funcionamento intelectual da criança. A sua inclusão nos programas educacionais era uma das medidas que Freud esperava que fossem tomadas numa transformação global sobre as questões da sexualidade.

\section{E, finalmente, ao impossível da prevenção}

As mudanças teóricas substanciais ocasionadas pela segunda tópica tornam ainda mais complexa a ideia de prevenção no pensamento freudiano. A posição esperançosa que acompanha Freud, até então, cede lugar ao ceticismo sobre os efeitos da psicanálise acerca dos rumos da civilização e do progresso da humanidade. Ao evidenciar a barreira do pulsional e da compulsão à repetição em Além do princípio do prazer, Freud (1920/2006e) questiona os benefícios da tarefa educativa, mas também os limites do trabalho analítico. E, sobretudo, são reafirmadas as desconfianças quanto às possibilidades de profilaxia.

Em um de seus últimos escritos, Freud (1937/2006i) volta a pensar na questão da prevenção, ao dissertar sobre as possibilidades do fim da análise. No artigo $A$ análise terminável e interminável, ele defende o argumento de que os desfechos da análise, quando são rápidos, pouco contribuem para o seu estudo, visto que não se dispõe de meios para predizer o que vai acontecer com o paciente. $\mathrm{O}$ autor ressalta que as perspectivas são otimistas; que, de início, o paciente tem condições de se livrar do conflito entre o ego e a pulsão de modo definitivo. Em segundo lugar, vem a possibilidade de, ao ser tratado, o paciente ser vacinado contra a ocorrência de outros conflitos desse tipo; e, em terceiro, que a psicanálise tem o poder, atuando profilaticamente, de despertar um conflito patogênico não revelado até então por nenhuma indicação, apontando que é aconselhável fazê-lo. Para ficar mais claro, utilizaremos as palavras do autor sobre prevenção:

[...] presume, de início, que há realmente uma possibilidade de livrar-se de um conflito instintual (ou, de modo mais correto, de um conflito entre o ego e um instinto) definitivamente e para todo o sempre; em segundo, que, enquanto estamos tratando alguém por causa de determinado conflito instintual, podemos, por assim dizer, vaciná-lo conta a possibilidade de quaisquer outro conflito desse tipo; e, em terceiro, que temos o poder, para fins de profilaxia, de despertar um conflito patogênico dessa espécie que não se está revelando, na ocasião, por nenhuma indicação, e que é aconselhável fazê-lo (FREUD, 1937/2006i).

Fractal, Rev. Psicol., v. 31 - n. 3, p. 313-319, 2019
Freud (1937/2006i) avança na discussão sobre as duas últimas possibilidades citadas. Propõe analisá-las juntamente, pois estão vinculadas entre si, e aprofunda um pouco a questão, quando diz que, no primeiro caso, considera como um resguardo contra o retorno de um mesmo conflito, e agora passa a pensar em como se resguardaria contra a possibilidade de substituição por outro conflito. E adianta que isso se mostra bastante ambicioso, embora o objetivo do artigo seja tornar claros os limites da terapia analítica.

Freud (1937/2006i) argumenta que, se um conflito pulsional não existe ou não está se manifestando, não se pode influenciá-lo até mesmo mediante análise. Após isso, o autor situa os meios pelos quais se poderia transformar um conflito pulsional latente até o momento em um conflito ativo. Um deles seria a possibilidade de provocar situações nas quais o conflito poderia vir à tona ou contentar-se em debatê-lo durante a análise e apontar a possibilidade de ele despertar. No caso da primeira opção, poderia se expressar de duas maneiras: na realidade ou na transferência. Segundo o autor:

Na profilaxia analítica contra os conflitos instintuais, portanto, os únicos métodos que entram em consideração são os outros dois que mencionamos: a produção artificial de novos conflitos na transferência (conflitos a que, afinal de contas, falta o caráter de realidade) e o despertar de tais conflitos na imaginação do paciente, falando-lhes sobre eles e tornando-os familiarizado com a sua possibilidade (FREUD, 1937/2006i).

Nos dois casos, contudo, o analista poderia expor o paciente a um sofrimento real, mediante a frustração e o represamento da libido. A intensão seria a de levar o paciente a um ponto culminante, com o objetivo de aumentar a força pulsional disponível para a sua solução. $\mathrm{O}$ autor chega à conclusão de que, em todas as fases do restabelecimento do paciente, deve-se lutar contra a inércia, visto que está pronto para se contentar com uma solução incompleta. Ao se falar, porém, de tratamento profilático de conflitos pulsionais não ativos, não seria suficiente regular sofrimentos que estão no paciente e que ele mesmo não pode evitar. Nesse caso, o analista teria que decidir lhe causar novos sofrimentos. Em relação a isso, o autor acredita ser melhor deixar a cargo do destino. Além das questões práticas que essa situação poderia ocasionar, existem também questões teóricas que impediriam a sua materialização, visto que o trabalho de análise progride melhor se as experiências patológicas do paciente estiverem alocadas no passado, do qual o ego possa estar a certa distância. $\mathrm{O}$ autor também alerta para a noção de que, em estados de crises agudas, a psicanálise tem pouco a fazer. Logo, criar um conflito decerto torna o trabalho de análise mais longo e problemático.

Freud (1937/2006i) utiliza como exemplo de profilaxia a vacinação, visto que o médico não produz a doença no paciente, apenas induz o aparecimento de uma pequena quantidade de algo mais leve. No caso da profilaxia analítica contra os conflitos pulsionais, os métodos que o autor via naquele momento como possíveis eram dois: a produção artificial de novos conflitos no processo da transferência (faltando-lhes o caráter de realidade) ou o 
despertar de conflitos na imaginação do paciente, mediante relatos sobre eles, de modo a familiarizá-lo com a possibilidade de sua ocorrência. No que se refere à primeira opção, ainda não experienciada, surgem dificuldades que impossibilitam sua concretização: no primeiro momento, o autor exibe que os pacientes não podem, por si próprios, trazer seus conflitos para a transferência, e o analista, por sua vez, não está capacitado para provocar os seus conflitos instituais com apoio na sua relação transferencial. Pode provocar certos sentimentos, todavia não existe um método para ocasionar isso, e chega à conclusão de que esses acontecimentos podem ter curso na análise por si mesmos. Além disso, tal conduta do analista pode ocasionar um efeito prejudicial sobre a transferência positiva.

Assim, sobra apenas um método, originalmente considerado, que consiste em falar para o paciente acerca da possibilidade de outros conflitos pulsionais e despertar sua expectativa de que esses conflitos possam vir a ocorrer com ele. $\mathrm{O}$ objetivo desse método seria o de ativar alguns dos conflitos apontados, em pequeno grau, mas de modo suficiente para serem trabalhados no tratamento. Aqui o autor assinala que esse resultado não ocorre, visto que o paciente escuta o que é dito, entretanto não tem a reação esperada; isto é, aumenta-se o conhecimento, mas nada se altera com procedência nele.

Freud (1937/2006i) compara essa possibilidade com os leitores da psicanálise, que, ao se verem perante os textos, são de certa forma estimulados por algumas passagens que remetem a si próprios, ou seja, que dizem respeito aos conflitos ativos naquele momento. $\mathrm{O}$ autor compara também às situações nas quais se fazem às crianças esclarecimentos de ordem sexual, sem se dizer se isso é necessário ou prejudicial. Freud (1937/2006i) garante que o efeito profilático dessa medida foi superestimado na época, visto que, após receberem essas explicações, as crianças passam a saber de algo que não sabiam antes, mas não fazem uso desse novo conhecimento. $\mathrm{O}$ autor argumenta que percebeu que a criança não tem nem pressa de sacrificar esse novo conhecimento, as teorias sexuais que podem ser consideradas como um crescimento natural que ela mesma constitui em harmonia com a sua organização libidinal imperfeita. Segundo ele, "por longo tempo após receberem esclarecimentos sexuais, elas se comportam como as raças primitivas que tiveram o cristianismo enfiado nelas, mas que continuam a adorar em segredo seus antigos ídolos" (FREUD, 1937/2006i, p. 267).

Vimos, assim, que é em Análise terminável e interminável que Freud se detém mais no que se refere à profilaxia. Entretanto, apesar de se alongar no tema e pensar em hipóteses para efetivar a prevenção no processo de análise, incluindo a possibilidade via transferência, o autor abdica, pelo menos no que se concebia como prevenção até então.

\section{Considerações}

O artigo revela uma evidente diversidade dos movimentos na abordagem freudiana da prevenção. Embora atento às possibilidades e limites de uma prática psicanalítica de caráter preventivo, Freud não se detém na análise mais rigorosa dessa temática.
As imprecisões da abordagem freudiana sobre a ideia de prevenção, mais do que inviabilizadoras de uma definição conceitual ou de uma interpretação conclusiva, impulsionam-nos ao trabalho de atualizar a teoria pelo incessante exercício da clínica. A aparente contradição decorrente da dualidade otimismo/ceticismo quanto aos efeitos terapêuticos da psicanálise nos faz, antes de tudo, duvidar e nos alerta quanto ao perigo de uma adesão rápida, quer seja à lógica normativa das práticas socioeducativas, quer seja aos novos paradigmas do campo da saúde. Por outro lado, ao não fechar o debate, o texto freudiano deixa aberto o caminho para a continuidade da reflexão, alimentada agora por novas questões advindas da clínica psicanalítica com bebês (LAZNIK, 1997; CULLERE-CRESPIN, 2004; JERUSALINSKY, 2002), mais recentemente inaugurada.

\section{Informações sobre as autoras:}

Beatriz Sernache de Castro Neves (iD) https://orcid.org/0000-0003-3744-0723

(9) http://lattes.cnpq.br/6996511785807277

Psicóloga graduada pela Universidade de Fortaleza - UNIFOR (2013), com mestrado em Psicologia pela UNIFOR (2015), e doutoranda em Saúde Coletiva pela Universidade Federal do Ceará - UFC. Docente do curso de Psicologia da Faculdade Ari de Sá. Psicóloga clínica. Psicóloga do Instituto da Primeira Infância IPREDE de 2013 a 2018 , onde fez atividades de preceptoria de diversas faculdades de Fortaleza. Com interesse nas seguintes áreas: psicanálise, saúde coletiva, infância, psicopatologia da infância, práticas institucionais e clínica precoce.

\section{Maria Celina Peixoto Lima \\ (iD) https://orcid.org/0000-0002-9305-079X \\ (9)} Possui graduação em Psicologia pela Universidade Federal do Ceará (1982), mestrado em Psicologia e Psicopatologia Clínica - Université Lyon 2 (1991), mestrado em Psicologia pela Pontifícia Universidade Católica de Campinas (1985), doutorado em Psicologia - Université Paris 13 (2002) e Pos-Doutorado Université Rennes 2 (2015). Atualmente é professora titular do PPG em Psicologia da Universidade de Fortaleza, psicanalista. Desenvolve pesquisas principalmente nos seguintes temas: psicanálise, laço social, discursos e práticas institucionais, psicopatologia da infância e da adolescência. E membro do Grupo de Trabalho da ANPEPP "Psicanalise e educação".

\section{Contribuições das autoras:}

Beatriz Sernache de Castro Neves foi responsável pela concepção, desenho e coleta de dados do estudo e elaboração do manuscrito. Maria Celina Peixoto Lima foi responsável pela concepção e revisão do manuscrito.

\section{Como citar este artigo:}

\section{ABNT}

NEVES, Beatriz Sernache de Castro; LIMA, Maria Celina Peixoto. Freud e a prevenção: um percurso de controvérsias. Fractal: Revista de Psicologia, Niterói, v. 31, n. 3, p. 313-319, set./dez. 2019. https://doi.org/10.22409/1984-0292/v31i3/5642

\section{APA}

Neves, B. S. C., \& Lima, M. C. P. (2019, Setembro/Dezembro). Freud e a prevenção: um percurso de controvérsias. Fractal: Revista de Psicologia, 31(3), 313-319. doi: https://doi.org/10.22409/19840292/v31i3/5642 


\section{Referências}

CASTEL, Robert. A gestão do risco. Rio de Janeiro: Francisco Alves, 1981.

CULLERE-CRESPIN, Graciella. A clínica precoce: o nascimento do humano. São Paulo: Casa do Psicólogo, 2004.

FREUD, Sigmund. A sexualidade na etiologia das neuroses (1898). In: SALOMÃO, Jayme (Org.). Obras Psicológicas Completas de Sigmund Freud. Rio de Janeiro: Imago, 2006a. v. 2, p. 55-79. Edição Standard Brasileira.

FREUD, Sigmund. Análise de uma fobia de um menino de cinco anos (1909). In: SALOMÃO, Jayme (Org.). Obras Psicológicas Completas de Sigmund Freud. Rio de Janeiro: Imago, 2006b. v. 10, p. 15-135. Edição Standard Brasileira.

FREUD, Sigmund. As perspectivas futuras da psicanálise (1910). In: SALOMÃO, Jayme (Org.). Obras Psicológicas Completas de Sigmund Freud. Rio de Janeiro: Imago, 2006c. v. 11, p. 143-156. Edição Standard Brasileira.

FREUD, Sigmund. O interesse científico da psicanálise (1913). In: SALOMÃO, Jayme (Org.). Obras Psicológicas Completas de Sigmund Freud. Rio de Janeiro: Imago, 2006d. v. 13, p. 169192. Edição Standard Brasileira

FREUD, Sigmund. Além do princípio do prazer (1920). In: SALOMÃO, Jayme (Org.). Obras Psicológicas Completas de Sigmund Freud. Rio de Janeiro: Imago, 2006e. v. 18, p. 17-74. Edição Standard Brasileira.

FREUD, Sigmund. A questão da análise leiga (1926). In: SALOMÃO, Jayme (Org.). Obras Psicológicas Completas de Sigmund Freud. Rio de Janeiro: Imago, 2006f. v. 20, p. 181256. Edição Standard Brasileira.

FREUD, Sigmund. O futuro de uma ilusão (1927). In: SALOMÃO, Jayme (Org.). Obras Psicológicas Completas de Sigmund Freud. Rio de Janeiro: Imago, 2006g. v. 23, p. 15-66. Edição Standard Brasileira.

FREUD, Sigmund. Conferência XXXIV (1933). In: SALOMÃO, Jayme (Org.). Obras Psicológicas Completas de Sigmund Freud. Rio de Janeiro: Imago, 2006h. v. 22, p. 145166. Edição Standard Brasileira.

FREUD, Sigmund. A análise terminável e interminável (1937). In: SALOMÃO, Jayme (Org.). Obras Psicológicas Completas de Sigmund Freud. Rio de Janeiro: Imago, 2006i. v. 23, p. 231274. Edição Standard Brasileira.

GOLSE, Anne. De la Médecine de la maladie a la Médecine de la santé. In: ARTIÈRES, Philippe; SILVA, Emmanuel da (Org.). Michel Foucault et la medicine : lectures et usages. Paris: KIMÉ, 2001. p. 273-300.

JERUSALINSKY, Julieta. Enquanto o futuro não vem: a psicanálise na clínica interdisciplinar com bebês. Salvador: Álgama, 2002.

LAJONQUIÈRE, Leandro de. Sigmund Freud: para uma educação além da pedagogia. Educação Temática Digital, Campinas, v. 8, n. esp., p. 1-19, 2006. https://doi.org/10.20396/ etd.v8i0.710

LAZNIK-PENOT, Marie Christine. Poderíamos pensar numa prevenção da Síndrome Autística? In: WANDERLEY, Daniele de Brito. (Org.). Palavras em torno do berço. Salvador: Álgama, 1997. p. 35-51.

MILLOT, Catherine. Freud antipedagogo. Rio de Janeiro: J. Zahar, 1987.

Fractal, Rev. Psicol., v. 31 - n. 3, p. 313-319, 2019
SCHIMIDT, Gleisson Roberto. Sigmund Freud, da psicoprofilaxia à educação psicanaliticamente esclarecida: um percurso. Paidéia, Ribeirão Preto, v. 21, n. 48, p. 119-127, 2011. http://dx.doi.org/10.1590/S0103-863X2011000100014 